\title{
Role of Pharmacists in Health Based Non-Governmental Organizations (NGO): Prospects and Future Directions
}

Mohamed Azmi Hassali*, Omar Thanoon Dawood, Saleh Karamah AL-Tamimi and Fahad Saleem

Discipline of Social and Administrative Pharmacy, School of Pharmaceutical Sciences, Universiti Sains Malaysia, Minden, Penang 11800, Malaysia

\begin{abstract}
In this era of globalization, there are many non-government organizations (NGO) that grow in the community. Nowadays, NGOs are becoming the medium for the community to voice out or be the one who lend their hand to help the community around them. In the health care profession, NGOs play an important role to help the people in the community to have a better health in the future. In order to move the state of health of the people in the community, NGOs should acknowledge the role of the pharmacist in their organizations. However, contribution of pharmacists in NGOs is essential because inappropriate assistance or incorrect assistance can lead to death of the consumers. In fact, pharmacists as experts in medicines, they will play important role in distribution the medications and educating the medicines consumers within NGOs. Pharmacists could help in relief efforts and they also help in humanitarian aid. Besides that, they could help in the equality in social and social justice for people in need. Although all these people in the NGOs are well educated but somehow, their knowledge alone does not suffice in helping the community towards a better health. There are still some NGOs that tend to ignore the role of the pharmacist in their organization. As they tend to ignore the existence of the pharmacist, the drug that they had distributed to the community will have higher chance of producing an adverse effect towards the consumer. In this essay, the roles of pharmacist in many sectors of the NGOs will be discussed further to open the eyes of the people in the NGOs about how important and useful pharmacists could be in their organization.
\end{abstract}

Keywords: Distribution; Procurement; Diseases; Drug; Antibiotics; Diabetes

\section{Introduction}

Traditionally, the pharmacy was regarded as a transitional discipline between the health and chemical sciences and as a profession charged with ensuring the safe use of medication [1].

Access to pharmacists is access to health. The role of pharmacy practice today is more on the pharmaceutical care of patients and scope of pharmacy is much more related to health care, including clinical services, reviewing safety and efficacy of medications and providing information on drug. Additionally, Pharmacy circulates in the art of preparing, compounding, stabilizing, preserving and dispensing of medication and provision of pharmaceutical care to improve the quality of life of patients [2].

In the old days, pharmacy mainly includes manufacturing and compounding the medicine. But, as the time passed by, the role of pharmacy practice has been separated to different field of pharmacy including hospital and community pharmacy. In hospital pharmacy, the pharmacist involves more in supporting drug distribution, whereas, for community pharmacy, the pharmacists are majorly involved in dispensing of medicine and patients consulting. The role of pharmacy nowadays more involves in provision of clinical pharmacy and pharmaceutical care. The role of pharmacists in the past, present and future has their specific duties and responsibilities [3].

NoNGOvernmental organizations (NGOs) play an important humanitarian role in both developing economics [4]. NGOs can be categorized based on their orientations and level of cooperation. The general public is expected to join the activities and receive the service. Participatory orientation is characterised by self-help projects where the local people contribute cash, land or labour in order to implement the project. Usually, cooperatives have this orientation. The empoweringoriented NGOs help the public to have a clearer understanding towards the social, political, and economic factors that affect their lives and to strengthen their awareness of their rights in their own lives. From the aspect of level of organization, there are communitybased organization, citywide organization, national organizations and international organizations $[5,6]$.

The NGO pharmacist is in charge of the management of the drug supply cycle, and is furthermore an important member of the larger health care team [3]. A few NGO's that are working in the field realize the crucial role of the pharmacist and the challenges that are faced by drug supply management. One of these NGOs is Medicins Sans Frontieres (MSF) - doctors without borders- a medical emergency organization. The role of the pharmacist in MSF is clearly defined. Therefore the pharmacist is well integrated into their drug supply system. Furthermore MSF is aware of the lack of drug regulatory systems in developing countries and the circulation of substandard and counterfeit medicines [7], thus the MSF chain system does not only covers the operational aspects as the quality is also monitored from headquarters levels by a team of pharmacists.

\section{The Role of Pharmacists in NGO}

In the past few years, NGOs have been active in primary health care. They mostly run their own projects, some fund and monitor local service-providing NGOs. According to the 2006 World Refugee

*Corresponding author: Mohamed Azmi Hassali, Discipline of Social and Administrative Pharmacy, School of Pharmaceutical Sciences, Universiti Sains Malaysia, Penang, Malaysia, E-mail: azmihassali@gmail.com

Received January 31, 2016; Accepted February 22, 2016; Published February 25, 2016

Citation: Hassali MA, Dawood OT, AL-Tamimi SK, Saleem F (2016) Role of Pharmacists in Health Based Non-Governmental Organizations (NGO): Prospects and Future Directions. Pharm Anal Acta 7: 467. doi:10.4172/2153-2435.1000467

Copyright: @ 2016 Hassali MA, et al. This is an open-access article distributed under the terms of the Creative Commons Attribution License, which permits unrestricted use, distribution, and reproduction in any medium, provided the original author and source are credited. 
survey conducted annually by the U.S. Committee for Refugees and Immigrants (USCRI), a staggering 33 million people worldwide are currently uprooted from their homes [8]. Out of that number, 12 million are refugees and asylum seekers. NGOs are considered to be the best establishment for reaching the poor and providing health care in an efficient and cost-effective way with many national governments not being able to supply sufficient health care [9]. In these humanitarian activities, pharmacists need to be recruited by NGO as they serve to ensure the refugees' access to essential medicines. Pharmacists have to play their role in choosing the best drugs and are responsible to reduce the transmission of infectious diseases, promoting optimal use of antibiotics and educating the refugees. Partners in Health (PIH), a Boston-based non-governmental organization, describes its mission as "caring for patients, alleviating the root causes of the diseases in specific communities and sharing learned lessons with the rest of the world", which is perfectly tailored for pharmacists [10]. Most importantly, pharmacists have a unique opportunity to help in the camps for refugees with desperate and most deserving people while advancing the NGOs' mission. Pharmacists together with NGOs could help and prepare for emergencies by developing procedures of standard operations, forms, and data management tools, which can be modified easily for surveillance activities in humanitarian emergency settings [11].

\section{Importance of Pharmacists in NGO}

\section{Drug supply system}

In relation to the role of pharmacists in NGOs, a pharmacist within $\mathrm{NGO}$ is responsible for the management of the drug supply cycle and is an integral part of the larger health care team [3]. Pharmacists play a rather significant role in NGOs regarding drug supply cycle as pharmacists will assume various functions ranging from the procurement of medicine supply, distribution of medicine and also counselling for the usage of drugs. The drug supply management system consists of 3 dimensions which is policy and legal framework (constructing policies regarding drug management), drug supply cycle (process of selection, procurement, distribution and usage of drugs), and management support (system management, human resources and more) [12].

\section{Ensuring the distribution of the right drugs}

Pharmacists are often known as the guardian of drugs and thus possess the knowledge of all drug uses and implications within their minds. Pharmacists assumes their role to give counselling and ensure the procurement of correct medications when private persons donate their drug as they often do not understand what medicines are needed during humanitarian aid activities. According to Germany's Institute for Medical Mission (DIFÄM), it costs around \$34 million to dispose of 17,000 tonnes of donated drugs which were useless in Bosnia-Herzegovina $[13,14]$. This shows that there is a role to be played by pharmacists within NGOs be it on the field as a volunteer themselves or in the regulatory field whereby they work together to produce guidelines for drug donations that are geared to the needs of developing countries and also in sync with WHO recommendations. In the guidelines formed by DIFÄM, Action Medeor, a German pharmaceutical NGO managed to send around 119,000 antibiotic pills from a German drug manufacturer to a hospital in Zimbabwe. When it comes to disaster relief, the speed of arrival of aid matters, therefore, pharmacists are required to ensure that the medical supply is accurate to the needs of the victims to save time and lives [15].

\section{Promoting public health awareness through NGO}

In Malaysia, NGOs have played important roles in promoting public health awareness. This can be seen through activities conducted by certain NGOs to reorient health services. For instance, Malaysia Diabetes Association has been conducting monthly counselling sessions regarding the topic of diabetes which is free to the public. Furthermore, promoting the role of Malaysian NGO in the safety of medicines provided another overview that the role of NGOs is really important in the provision of safe use of medicines [16]. Through such events, healthcare professionals will discuss on the selected topic in order to increase public awareness on diabetes and the ways to prevent it. Pharmacists too, play a role in inculcating a healthy mindset in the general public as the roles of a pharmacist are no longer confined to dispensary and is broadened to other fields such as public health. Beyond the shores of Malaysia, NGOs are also engaged in various health promotion campaigns in which healthcare professionals such as doctors and pharmacists play an essential role [17]. International organizations such as Joint United Nations Programme on HIV / AIDS (UNAIDS) inspires the world in achieving universal access to HIV prevention, treatment, care and support. Pharmacists will play a role in educating the public regarding the effectiveness of HIV therapies and also in the field of research for new HIV drugs [18-21].

\section{Pharmacists role in NGOs relief efforts}

Pharmacists play an important role when it comes to relief efforts within disaster regions as they are more able to help in reducing disease transmission, ensuring proper use of antibiotics and also in educating the patients and the public. Regarding reduction of disease transmission, pharmacists will be involved in the process of decision making in the disaster region. Pharmacists are also more knowledgeable in terms of quality control in any settings (e.g. refugee camps) when it comes to medications to ensure proper health standards and also safety measures [22]. In addition to the use of antibiotics, optimal use of microbial agents is extremely important to prevent the emergence of more antibiotic resistant bacteria. This is extremely crucial especially in refugee camps as time is of the essence during disaster aid, effectiveness of the drug must be ensured to prevent potential adverse drug reactions in order to reduce the amount of casualties [22]. Besides that, pharmacists play an important role in educating the patients and the public. Reducing contamination and infection in a refugee camp is important because the victims are more susceptible to infections due to lack of nutrients and also trauma $[23,24]$. Pharmacists assume their role in various platforms such as public talks to inform the general public regarding ways to prevent transmission of infection and also decontamination of products [25].

\section{Roles of pharmacist in the society}

Only when the pharmacist has been accepted as a vital member of the health care team can the necessary supporting services be organized with the professionalism that they demand [3]. The few qualified pharmacists in humanitarian health organizations are mainly involved in managing advocacy campaigns or working in headquarter offices. The professional gap is the absence of pharmacists in the health team in field projects [26].

The pharmacy's opportunity to mature as a profession by accepting its social responsibility to reduce preventable drug-related morbidity and motility is explored. Pharmacy has shed the apothecary role but has not yet been restored to its erstwhile importance in medical care [27]. The roles of pharmacists had changes a lot in last few decades. Primarily, the roles of pharmacists are compounding and formulating medicines. However, those activities became less important since the availability of prefabricated drug products and adoption of patient-oriented roles for pharmacists. Apart from treating the disease, the goal of health 
care system is also to prevent it. Thus, health care workers cannot rely exclusively on the clinical origin of diseases and treatment modalities but also targeted on individual lifestyles and the need for social and environmental change. In order to achieve the best pharmaceutical care service, a good understanding on patients' behaviour and psychology should be learned thoroughly $[28,29]$. Changing the focus of practice from products and biological systems to ensuring the best drug therapy and patient safely will raise the pharmacy's level of responsibility and require philosophical, organizational and functional changes. It will be necessary to set new practice standards, establish cooperative relationships with other healthcare professions and determine strategies for marketing pharmaceutical care. Pharmacy's reprofesionalization will be completed only when all pharmacists accept their social mandate to ensure the safe and effective drug therapy of the individual patient [3].

\section{Role of pharmacists for humanitarian aid}

The landscape of pharmacy has drastically changed over the past decade as it has become a field which is much more patient oriented. The field has changed. Now it plays more of a clinical role with more patient interaction. In fact, pharmacists can help out during disasters that happen in the whole world. For instance, in March 11, 2011, an 8.9 magnitude earthquake and subsequent tsunami overwhelmed the cooling systems of an aging reactor along Japan's northeast coastline which caused almost 10,000 victims died [30]. From this view, we can see pharmacists must play an important role on how to make sure the death rate can be reduced during disaster. Pharmacists are not only responsible to prescribe best medicine to people in order to obtain good health. However, they also play a role as motivator to give moral supports in order to make sure the continuity of persons' life. The trusting relationship with the pharmacist offers a strong basis for the psychological and social support needed by the people in disaster [31]. Some people who are facing loss of their family members or their loved ones because of disaster having a great chance of rejecting any medication due to being traumatized and they do not see any importance of it anymore.

The role of pharmacists in humanitarian activities during disaster cannot be questioned anymore because of lots of contributions they had given to make sure the continuity and the security of peoples' life and health. However, the need of pharmacist in NGOs can be used to create training programmes for pharmacists to go into humanitarian situations or for those who live in areas which are at high risk of a natural disaster, such as an earthquake, tsunami, hurricane, volcanic eruption, flood or epidemic. It can also be used to assemble an accredited list of pharmacists with experience in the area of humanitarian aid as a resource for NGOs and to create a catalogue of formularies and pharmacy contacts in countries identified as high risk, so that in a disaster all potential medicine donors can liaise with local services to ensure that medicines are appropriate, handled and stored safely [26].

In a nutshell, it is compulsory for all pharmacists to put an eye on the humanity as pharmacy is one of the fields that we make interaction with people from the whole world. Therefore, pharmacists must get essential skills so that they can play a role in humanitarian aid and development.

\section{Conclusion}

A pharmacist is an important healthcare profession that provides medicines and advises the patients and health care providers on the selection, dosages, interactions and side effects of medications.
Pharmacists are very needed not only in public health sector but also have a high demand in non-governmental organizations (NGO). The contribution of pharmacists in NGOs is essential because inappropriate assistance can lead to death. Pharmacists are an integral part of the larger health care team and are responsible for the management of drug supply cycle within an NGO. NGOs are considered to be the best establishment for providing health care and reaching the poor especially. Besides, choosing the best drugs is vital for pharmacists as they are responsible in reducing the transmission of infectious diseases, promoting optimal use of antibiotics and educating the refugees about healthcare. Hence, to conclude, the involvement of pharmacists can relieve the efforts of NGOs worldwide.

Pharmacists play vital roles not only in the health care system through the medicine but also in aiding the non-governmental organization (NGO) to practice public health efficiently. General public should know that the role of a pharmacist is not only in dispensary but also broadened to other fields such as social pharmacy and public health. This is due to the roles of pharmacists that have expanded to administrative and public health functions. Non-governmental organizations (NGOs) engaged actively in various health promotions in which healthcare professionals act as the primary role.

Nowadays, pharmacists are also actively involved promoting health to the public and healthcare professionals on drugs-related events. Besides that, the importance of pharmacists within NGOs is ensuring the distribution of the right drugs. Pharmacists are required to ensure that the medicines or drugs supplied are accurate to the needs of the patients. Lack involvement of pharmacists in international NGOs as well as local NGOs due to the less understanding of pharmacists' role besides. Pharmacists have a unique opportunity to help desperate and most deserving people while advancing the NGOs mission. Involvement of pharmacists in NGOs required a new set of skills such as learning foreign languages and cultural awareness. In addition, pharmacists are knowledgeable of different states of many disease and drug therapy managements could be critical in preventing health crises.

\section{References}

1. Pearson GJ (2007) Evolution in the practice of pharmacy--not a revolution! CMAJ 176: 1295-1296

2. (2006) Developing pharmacy practice - A focus on patient care, World Health Organization, Genebra.

3. (1994) World Health Organization, The Role of the Pharmacist in the Healthcare System in Report of a WHO Meeting, World Health Organization, Tokyo, Japan.

4. Gursky EA (2015) Rising to the Challenge: The Ebola Outbreak in Sierra Leone and How Insights Into One NoNGOvernmental Organization's Response Can Inform Future Core Competencies. Disaster Med Public Health Prep 9: 554-557.

5. Banks N, Hulme D (2012) The role of NGOs and civil society in development and poverty reduction, Brooks World Poverty Institute: University of Manchester.

6. Okma KG, Kay A, Hockenberry S, Liu J, Watkins S (2015) The changing role of health-oriented international organizations and noNGOvernmental organizations. Int J Health Plann Manage.

7. Caudron JM (2008) Substandard medicines in resource-poor settings: a problem that can no longer be ignored Médicaments sous-standard dans les milieux défavorisés: un problème qui ne peut plus être ignoré. Revue Medicamentos sub-estándar en lugares con pocos recursos: un problema que no puede ser ignorado por más tiempo. Revisión. Tropical Medicine \& International Health 13: 1062-1072.

8. (2006) United States Committee for Refugees and Immigrants. U.S. Committee for Refugees and Immigrants World Refugee Survey 2006 - Syria.

9. Cousins W (1991) Non-governmental initiatives in ADB, in The Urban Poor and Basic Infrastructure Services in Asia and the Pacific: Asian Development Bank, Manila. 
Citation: Hassali MA, Dawood OT, AL-Tamimi SK, Saleem F (2016) Role of Pharmacists in Health Based Non-Governmental Organizations (NGO): Prospects and Future Directions. Pharm Anal Acta 7: 467. doi:10.4172/2153-2435.1000467

10. Litchfield SM (2010) How to help when disaster strikes. AAOHN J 58: 85-87.

11. Magloire R, Mung HK, Cookson ST, Tappero J, Barzilayo E, et al. (2010) Rapid establishment of an internally displaced persons disease surveillance system after an earthquake --- Haiti, 2010. MMWR Morb Mortal Wkly Rep 59: 939-945.

12. (2004) World Health Organization, Management of Drugs at Health Centre Level, WHO Regional Office for Africa: Brazzaville.

13. (1999) Guidelines for Drug Donations, in an intergagency consensus document published by the WHO Department of Essential Drugs and Other Medicines on behalf of the organizations listed, World Health Organization: Geneva.

14. Hogerzeil HV, Couper MR, Gray R (1997) Guidelines for drug donations. BM 314: 737-740.

15. (2006) Devenney A, The role of the pharmacist in palliative care. Irish Pharmacy Journal 84: 249

16. Alshakka MA (2010) Promoting the role of Malaysian non-governmental organizations in the safety of medicines. Internet Journal of Third World Medicine 9.

17. Idris A (2012) Malaysian non-governmental organizations (NGOs) and humanitarian issues in Gaza, Palestine. Jurnal Antarabangsa Kajian Asia Barat 4: $49-78$

18. Litsios S (2004) Primary Health Care, WHO and the NGO Community. Development 47: 57-63.

19. (2016) The Fogarty International Center-NIH. NoNGOvernmental Organizations (NGOs) Working in Global Health Research.

20. Tseng A, Foisy M, Hughes CA, Kelly D, Chan S, et al. (2012) Role of the Pharmacist in Caring for Patients with HIVIAIDS: Clinical Practice Guidelines. Can J Hosp Pharm 65: 125-145.
21. March K, Mak M, Louie SG (2007) Effects of pharmacists' interventions on patient outcomes in an HIV primary care clinic. American Journal of HealthSystem Pharmacy 64: 2574-2578.

22. (2010) ASHP statement on the pharmacist's role in antimicrobial stewardship and infection prevention and control. Am J Health Syst Pharm 67: 575-577.

23. Ross M (2015) Pharmacists Help Refugees Navigate US Medicine, Pharmacy Times.

24. Taheri $L$ (2010) After disasters diseases develop, and there is an emerging role for pharmacy. The Pharmaceutical Journal 285: 263.

25. Balidemaj F, Balidemaj A (2014) Assessment of Role in Non-Governmental Organizations and Their Humanitarian Effort in Refugee Camps Worldwide. International Advisory Board 68.

26. Villacorta-Linaza $R$ (2009) Bridging the gap: the role of pharmacists in managing the drug supply cycle within non-governmental organizations. Int $\mathrm{J}$ Health Plann Manage 24 Suppl 1: S73-86.

27. Hepler CD, Strand LM (1990) Opportunities and responsibilities in pharmaceutical care. Am J Hosp Pharm 47: 533-543.

28. Hassali MA, Shafie AA, Al-Haddad MS, Abduelkarem AR, Ibrahim MI, et al. (2011) Social pharmacy as a field of study: the needs and challenges in global pharmacy education. Res Social Adm Pharm 7: 415-420.

29. Braveman PA, Egerter SA, Mockenhaupt RE (2011) Broadening the focus: the need to address the social determinants of health. Am J Prev Med 40: S4-18.

30. Jorgenson JA (2010) Specialty pharmacy: Status and future direction. The American Journal of Pharmacy Benefits 2: 347-348.

31. Malaysia MoH (2010) Tenth country health plan: 1 care for 1 Malaysia. 